\title{
LINC01414/LINC00824 genetic polymorphisms in association with the susceptibility of chronic obstructive pulmonary disease
}

\author{
Xiaoman Zhou ${ }^{\dagger}$, Yunjun Zhang ${ }^{\dagger}$, Yutian Zhang, Quanni Li, Mei Lin, Yixiu Yang, Yufei Xie and Yipeng Ding ${ }^{*}$
}

\begin{abstract}
Objective: Chronic obstructive pulmonary disease (COPD) is a complicated multi-factor, multi-gene disease. Here, we aimed to assess the association of genetic polymorphisms in LINC01414/ LINC00824 and interactions with COPD susceptibility.

Methods: Three single nucleotide polymorphisms (SNPs) in LINC01414/LINC00824 was genotyped by Agena MassARRAY platform among 315 COPD patients and 314 controls. Logistic analysis adjusted by age and gender were applied to estimate the genetic contribution of selected SNPs to COPD susceptibility.

Results: LINC01414 rs699467 (OR=0.73, 95\% Cl 0.56-0.94, $p=0.015)$ and LINC00824 rs7815944 (OR=0.56, 95\% Cl $0.31-0.99, p=0.046)$ might be protective factors for COPD occurrence, while LINC01414 rs 298207 (OR = 2.88, 95\% $\mathrm{Cl} 1.31-6.31, p=0.008$ ) risk-allele was related to the increased risk of COPD in the whole population. Rs7815944 was associated with the reduced risk of COPD in the subjects aged $>70$ years $(O R=0.29, p=0.005)$. Rs6994670 (OR $=0.57$, $p=0.007)$ contribute to a reduced COPD risk, while rs298207 ( $\mathrm{OR}=7.94, p=0.009)$ was related to a higher susceptibility to COPD at age $\leq 70$ years. Rs298207 ( $\mathrm{OR}=2.54, p=0.043)$ and rs7815944 (OR $=0.43, p=0.028)$ variants was associated COPD risk among males. Rs7815944 (OR=0.16, $p=0.031)$ was related to the reduced susceptibility of COPD in former smokers. Moreover, the association between rs298207 genotype and COPD patients with dyspnea was found $(\mathrm{OR}=0.50, p=0.016)$, and rs7815944 was related to COPD patients with wheezing (OR=0.22, $p=0.008)$.
\end{abstract}

Conclusion: Our finding provided further insights into LINC01414/LINC00824 polymorphisms at risk of COPD occurrence and accumulated evidence for the genetic susceptibility of COPD.

Keywords: Chronic obstructive pulmonary disease, LINC01414/LINC00824, Polymorphism, Smoking status, Clinical symptom

\section{*Correspondence: ypding@263.net}

${ }^{+}$Xiaoman Zhou and Yunjun Zhang are co-first authors.

Department of General Practice, Hainan General Hospital, \#19, Xiuhua

Road, Xiuying District, Haikou 570311, Hainan, People's Republic of China

\section{Introduction}

Chronic obstructive pulmonary disease (COPD) is a severely disabling chronic lung disease. COPD is characterized by persistent airflow limitation of respiratory systems due to emphysema and obstructive bronchiolitis [1]. The airflow limitation is caused by the large exposure of lung to harmful particles or gases. At present, the high incidence of COPD exceeds 250 million, which 
Table 1 Characteristics of patients with COPD patients and controls

\begin{tabular}{|c|c|c|c|}
\hline Variable & Cases & Controls & $p$ \\
\hline$n$ & 315 & 314 & \\
\hline Age, $($ mean $\pm S D)$ year & $71.9 \pm 10.1$ & $71.2 \pm 6.8$ & 0.307 \\
\hline Gender (male/female), n & $239 / 76$ & $237 / 77$ & 0.926 \\
\hline Smoking (current/former/never/unavailable), n & $83 / 64 / 166 / 2$ & $34 / 18 / 118 / 114$ & \\
\hline BMI, ( $\leq 24 \mathrm{~kg} / \mathrm{m}^{2} />24 \mathrm{~kg} / \mathrm{m}^{2} /$ unavailable), n & $251 / 29 / 35$ & $67 / 78 / 169$ & \\
\hline COPD with complication (yes/no/unavailable), $\mathrm{n}$ & $93 / 174 / 48$ & & \\
\hline COPD with wheezing & $153 / 123 / 39$ & & \\
\hline COPD with dyspnea & $115 / 166 / 34$ & & \\
\hline COPD with chest distress & 102/179/34 & & \\
\hline respiratory rate, times/min & $22.3 \pm 2.5$ & & \\
\hline pulse rate, times/min & $86.3 \pm 11.7$ & & \\
\hline FVC, L & $2.0 \pm 0.7$ & & \\
\hline FEV1, L & $1.1 \pm 0.6$ & & \\
\hline FEV1/FVC, \% & $51.4 \pm 11.8$ & & \\
\hline \multicolumn{4}{|l|}{ GOLD spirometric grade, $\mathrm{n}(\%)$} \\
\hline 1 & $34(10.8 \%)$ & & \\
\hline 2 & $107(46.7 \%)$ & & \\
\hline 3 & $102(32.4 \%)$ & & \\
\hline 4 & $32(10.2 \%)$ & & \\
\hline
\end{tabular}

COPD chronic obstructive pulmonary disease, BMI body mass index, FVC including forced vital capacity, FEV1 forced the first second of expiratory volume, GOLD Global Initiative for Chronic Obstructive Lung Disease

$p$ values were calculated by $x^{2}$ test or the Student's $t$ test

Table 2 The information about the candidate SNPS and the association with COPD in the allele model

\begin{tabular}{|c|c|c|c|c|c|c|c|c|c|c|c|}
\hline \multirow[t]{2}{*}{ Gene } & \multirow[t]{2}{*}{ SNP ID } & \multirow[t]{2}{*}{ Chr: position } & \multirow{2}{*}{$\begin{array}{l}\text { Alleles } \\
\text { (Alt/Ref) }\end{array}$} & \multicolumn{2}{|l|}{ MAF } & \multirow[t]{2}{*}{ Call rate (\%) } & \multicolumn{3}{|l|}{ HWE } & \multirow[t]{2}{*}{ OR $(95 \% \mathrm{Cl})$} & \multirow[t]{2}{*}{$p$} \\
\hline & & & & Cases & Controls & & $\mathrm{O}(\mathrm{HET})$ & $\mathrm{E}(\mathrm{HET})$ & $p$ & & \\
\hline LINC01414 & rs6994670 & $8: 65,191,812$ & $\mathrm{G} / \mathrm{A}$ & 0.214 & 0.273 & 99.8 & 0.393 & 0.397 & 0.887 & $0.73(0.56-0.94)$ & $0.015^{*}$ \\
\hline LINC01414 & rs298207 & $8: 65,282,597$ & $\mathrm{~A} / \mathrm{G}$ & 0.229 & 0.189 & 98.4 & 0.320 & 0.307 & 0.578 & $1.27(0.97-1.68)$ & 0.086 \\
\hline LINC00824 & rs7815944 & $8: 129,427,518$ & $\mathrm{G} / \mathrm{A}$ & 0.265 & 0.304 & 99.8 & 0.390 & 0.423 & 0.181 & $0.83(0.65-1.06)$ & 0.131 \\
\hline
\end{tabular}

Bold indicate that $p<0.05$ means the data is statistically significant

COPD chronic obstructive pulmonary disease, SNP single nucleotide polymorphism, MAF minor allele frequency, HWE Hardy-Weinberg equilibrium, $O(H E T)$ observed heterozygotes, $E(H E T)$ expected heterozygotes

is the third leading cause of death in the world, and it is estimated to cause 4 million deaths every year $[2,3]$. In China, COPD caused over 0.9 million deaths is related to several public health problems including pollution, an aging population, and smoking $[4,5]$. COPD is a complicated multi-factor, multi-gene disease. Several studies displayed that the occurrence of COPD is associated with various factors such as tobacco smoking, air pollution, pulmonary tuberculosis, occupational exposure and genetic factors [6]. Increasing evidence suggested that genetic polymorphisms exert an important role in COPD occurrence and development [7-9].

Long non-coding RNAs (lncRNAs) is one of the key members of ncRNA family, with greater than 200 nucleotides, participating in the regulators of genetic expression and regulation [10]. Recent study has demonstrated that lncRNAs could contribute to the pathogenesis of respiratory diseases, including COPD [11]. Abnormal expression or function of IncRNAs has been considered to be involved in the development and progression of COPD [12, 13]. Recently, several studies reported some IncRNA gene polymorphisms to the susceptibility of COPD such as PVT1, MiR-146a, and $n s v 823469$ [14, 15]. Previously, abnormal expression of LINC00824 was associated with smoking [16]. However, the contribution of LINCO1414/LINC00824 genetic polymorphisms to COPD predisposition remains unclear. 
Table 3 Association between candidate SNPs and COPD susceptibility

\begin{tabular}{|c|c|c|c|c|c|c|}
\hline \multirow[t]{2}{*}{ SNP ID } & \multirow[t]{2}{*}{ Model } & \multirow[t]{2}{*}{ Genotype } & \multirow[t]{2}{*}{ Case } & \multirow[t]{2}{*}{ Control } & \multicolumn{2}{|c|}{ Adjusted by age and gender } \\
\hline & & & & & OR $(95 \% \mathrm{Cl})$ & $p$ \\
\hline \multirow{8}{*}{$\begin{array}{l}\text { LINC01414 } \\
\text { rs6994670 }\end{array}$} & \multirow[t]{3}{*}{ Genotype } & AA & 194 & 166 & 1 & \\
\hline & & $A G$ & 107 & 123 & $0.75(0.53-1.04)$ & 0.085 \\
\hline & & GG & 14 & 24 & $0.51(0.25-1.02)$ & 0.056 \\
\hline & \multirow[t]{2}{*}{ Dominant } & $\mathrm{AA}$ & 194 & 166 & 1 & \\
\hline & & $A G-G G$ & 121 & 147 & $0.71(0.51-0.97)$ & $0.034^{*}$ \\
\hline & \multirow[t]{2}{*}{ Recessive } & $A A-A G$ & 301 & 289 & 1 & \\
\hline & & GG & 14 & 24 & $0.57(0.29-1.13)$ & 0.107 \\
\hline & Log-additive & - & - & - & $0.73(0.56-0.95)$ & $0.018^{*}$ \\
\hline \multirow{8}{*}{$\begin{array}{l}\text { LINC01414 } \\
\text { rs298207 }\end{array}$} & \multirow[t]{3}{*}{ Genotype } & GG & 192 & 201 & 1 & \\
\hline & & GA & 94 & 99 & $1.00(0.71-1.41)$ & 0.990 \\
\hline & & $\mathrm{AA}$ & 24 & 9 & $2.87(1.30-6.36)$ & $0.009^{*}$ \\
\hline & \multirow[t]{2}{*}{ Dominant } & GG & 192 & 201 & 1 & \\
\hline & & GA-AA & 118 & 108 & $1.15(0.83-1.60)$ & 0.400 \\
\hline & \multirow[t]{2}{*}{ Recessive } & GG-GA & 286 & 300 & 1 & \\
\hline & & $\mathrm{AA}$ & 24 & 9 & $2.88(1.31-6.31)$ & $0.008^{*}$ \\
\hline & Log-additive & - & - & - & $1.27(0.97-1.66)$ & 0.085 \\
\hline \multirow{8}{*}{$\begin{array}{l}\text { LINC00824 } \\
\text { rs7815944 }\end{array}$} & \multirow[t]{3}{*}{ Genotype } & $\mathrm{AA}$ & 168 & 157 & 1 & \\
\hline & & $A G$ & 127 & 122 & $0.96(0.69-1.34)$ & 0.828 \\
\hline & & GG & 20 & 34 & $0.55(0.30-0.99)$ & $0.047^{*}$ \\
\hline & \multirow[t]{2}{*}{ Dominant } & $\mathrm{AA}$ & 168 & 157 & 1 & \\
\hline & & $A G-G G$ & 147 & 156 & $0.87(0.64-1.20)$ & 0.401 \\
\hline & \multirow[t]{2}{*}{ Recessive } & $A A-A G$ & 295 & 279 & 1 & \\
\hline & & GG & 20 & 34 & $0.56(0.31-0.99)$ & $0.046^{*}$ \\
\hline & Log-additive & -- & -- & -- & $0.83(0.65-1.06)$ & 0.128 \\
\hline
\end{tabular}

$p$ values were calculated by logistic regression analysis adjusted by age and gender Bold indicate that $p<0.05$ means the data is statistically significant

COPD chronic obstructive pulmonary disease, SNP single nucleotide polymorphism, OR odds ratio, $95 \% \mathrm{Cl} 95 \%$ confidence interval

Here, we genotyped three polymorphisms in LINC01414/LINC00824 to assess the genetic association of variants and interactions with COPD susceptibility among the Chinese Han population. Furthermore, the heterogeneity of relationship among subgroups (defined by age, gender and smoking status) and the correlation of selected polymorphisms with clinical symptoms of COPD patients were explored.

\section{Materials and methods}

\section{Study subjects}

A total of 315 COPD patients and 314 healthy controls were enrolled in the present study from Hainan General Hospital. All subjects were ethnic Han Chinese population. COPD patients were diagnosed based on the Global Initiative for Chronic Obstructive Lung Disease (GOLD) [17]. Patients with lung cancer, asthma, tuberculosis, interstitial fibrosis, bronchiectasis, and other respiratory diseases were excluded. Healthy controls who had no cancer history, respiratory diseases, inflammatory or immune diseases were recruited. We collected the demographic and clinical data of all subjects from the questionnaires and medical records. The study was approved by the medical ethics committee of Hainan General Hospital and was in the Declaration of Helsinki. All the subjects signed a written informed consent.

\section{SNPs genotyping}

Peripheral blood samples $(5 \mathrm{~mL})$ were collected from each subject into EDTA tubes. A commercially available DNA extraction Kits (GoldMag Co. Ltd, Xi'an, China) was used for the extraction of genomic DNA. Three single nucleotide polymorphisms (SNPs) including rs6994670 and rs298207 in LINC01414, rs7815944 in LINC00824 were selected based on the minor allele frequency $(\mathrm{MAF})>0.05$ from 1000 Genomes Project database, Hardy-Weinberg equilibrium (HWE) $>0.05$, and the calling rate $>98 \%$. Agena MassARRAY platform (Agena, San Diego, CA, USA) performed the process of 
Table 4 Association between polymorphisms and COPD risk stratified by age and gender

\begin{tabular}{|c|c|c|c|c|c|c|c|c|c|c|}
\hline SNP ID & Model & Genotype & Case & Control & OR $(95 \% \mathrm{Cl})$ & $p$ & Case & Control & OR $(95 \% \mathrm{Cl})$ & $p$ \\
\hline \multirow{11}{*}{$\begin{array}{l}\text { Age } \\
\text { LINC01414 } \\
\text { rs6994670 }\end{array}$} & & & \multicolumn{4}{|c|}{$>70$ years } & \multicolumn{4}{|c|}{$\leq 70$ years } \\
\hline & \multirow[t]{2}{*}{ Allele } & A & 297 & 268 & 1 & & 198 & 187 & 1 & \\
\hline & & G & 79 & 84 & $0.85(0.60-1.20)$ & 0.356 & 56 & 87 & $0.61(0.41-0.90)$ & $0.012^{*}$ \\
\hline & \multirow[t]{3}{*}{ Genotype } & $\mathrm{AA}$ & 116 & 102 & 1 & & 78 & 64 & 1 & \\
\hline & & $A G$ & 65 & 64 & $0.94(0.59-1.47)$ & 0.776 & 42 & 59 & $0.57(0.33-0.97)$ & $0.037^{*}$ \\
\hline & & GG & 7 & 10 & $0.56(0.20-1.57)$ & 0.271 & 7 & 14 & $0.33(0.12-0.90)$ & $0.031^{*}$ \\
\hline & \multirow[t]{2}{*}{ Dominant } & $\mathrm{AA}$ & 116 & 102 & 1 & & 78 & 64 & 1 & \\
\hline & & $A G-G G$ & 72 & 74 & $0.88(0.57-1.36)$ & 0.569 & 49 & 73 & $0.52(0.31-0.86)$ & $0.012^{*}$ \\
\hline & \multirow[t]{2}{*}{ Recessive } & AA-AG & 181 & 166 & 1 & & 120 & 123 & 1 & \\
\hline & & GG & 7 & 10 & $0.57(0.21-1.59)$ & 0.285 & 7 & 14 & $0.42(0.16-1.12)$ & 0.083 \\
\hline & Log-additive & - & & & $0.85(0.59-1.23)$ & 0.385 & & & $0.57(0.38-0.86)$ & $0.007^{*}$ \\
\hline \multirow{10}{*}{$\begin{array}{l}\text { LINC01414 } \\
\text { rs298207 }\end{array}$} & \multirow[t]{2}{*}{ Allele } & G & 294 & 287 & 1 & & 184 & 214 & 1 & \\
\hline & & A & 78 & 63 & $1.21(0.84-1.75)$ & 0.315 & 64 & 54 & $1.38(0.91-2.08)$ & 0.126 \\
\hline & \multirow[t]{3}{*}{ Genotype } & GG & 118 & 119 & 1 & & 74 & 82 & 1 & \\
\hline & & GA & 58 & 49 & $1.24(0.77-2.00)$ & 0.379 & 36 & 50 & $0.84(0.48-1.44)$ & 0.521 \\
\hline & & AA & 10 & 7 & $1.40(0.50-3.90)$ & 0.522 & 14 & 2 & $7.94(1.69-37.21)$ & $0.009^{*}$ \\
\hline & \multirow[t]{2}{*}{ Dominant } & GG & 118 & 119 & 1 & & 74 & 82 & 1 & \\
\hline & & GA-AA & 68 & 56 & $1.26(0.80-1.98)$ & 0.317 & 50 & 52 & $1.1(0.66-1.83)$ & 0.726 \\
\hline & \multirow[t]{2}{*}{ Recessive } & GG-GA & 176 & 168 & 1 & & 110 & 132 & 1 & \\
\hline & & AA & 10 & 7 & $1.31(0.47-3.62)$ & 0.602 & 14 & 2 & $8.47(1.83-39.24)$ & $0.006^{*}$ \\
\hline & Log-additive & -- & & & $1.21(0.83-1.76)$ & 0.311 & & & $1.38(0.91-2.11)$ & 0.134 \\
\hline \multirow{10}{*}{$\begin{array}{l}\text { LINC00824 } \\
\text { rs7815944 }\end{array}$} & \multirow[t]{2}{*}{ Allele } & A & 278 & 235 & 1 & & 185 & 201 & 1 & \\
\hline & & G & 98 & 117 & $0.71(0.51-0.97)$ & $0.034^{*}$ & 69 & 73 & $1.03(0.70-1.51)$ & 0.892 \\
\hline & \multirow[t]{3}{*}{ Genotype } & AA & 99 & 82 & 1 & & 69 & 75 & 1 & \\
\hline & & $A G$ & 80 & 71 & $0.90(0.57-1.42)$ & 0.653 & 47 & 51 & $1.02(0.60-1.72)$ & 0.951 \\
\hline & & GG & 9 & 23 & $0.29(0.12-0.68)$ & $0.005^{*}$ & 11 & 11 & $1.03(0.40-2.61)$ & 0.956 \\
\hline & \multirow[t]{2}{*}{ Dominant } & $\mathrm{AA}$ & 99 & 82 & 1 & & 69 & 75 & 1 & \\
\hline & & AG-GG & 89 & 94 & $0.75(0.49-1.16)$ & 0.193 & 58 & 62 & $1.02(0.62-1.67)$ & 0.943 \\
\hline & \multirow[t]{2}{*}{ Recessive } & $A A-A G$ & 179 & 153 & 1 & & 116 & 126 & 1 & \\
\hline & & GG & 9 & 23 & $0.30(0.13-0.70)$ & $0.005^{*}$ & 11 & 11 & $1.02(0.41-2.53)$ & 0.966 \\
\hline & Log-additive & - & & & $0.68(0.48-0.95)$ & $0.023^{*}$ & & & $1.02(0.69-1.49)$ & 0.941 \\
\hline Gender & & & Male & & & & Female & & & \\
\hline LINC01414 & Allele & G & 367 & 379 & 1 & & 111 & 122 & 1 & \\
\hline rs298207 & & A & 107 & 91 & $1.21(0.89-1.66)$ & 0.226 & 35 & 26 & $1.48(0.84-2.61)$ & 0.176 \\
\hline & Genotype & GG & 147 & 151 & 1 & & 45 & 50 & 1 & \\
\hline & & GA & 73 & 77 & $0.98(0.66-1.46)$ & 0.932 & 21 & 22 & $1.06(0.51-2.18)$ & 0.878 \\
\hline & & $\mathrm{AA}$ & 17 & 7 & $2.53(1.02-6.28)$ & $0.046^{*}$ & 7 & 2 & $3.99(0.77-20.64)$ & 0.099 \\
\hline & Dominant & GG & 147 & 151 & 1 & & 45 & 50 & 1 & \\
\hline & & GA-AA & 90 & 84 & $1.11(0.76-1.62)$ & 0.582 & 28 & 24 & $1.29(0.66-2.55)$ & 0.456 \\
\hline & Recessive & GG-GA & 220 & 228 & 1 & & 66 & 72 & 1 & \\
\hline & & AA & 17 & 7 & $2.54(1.03-6.26)$ & $0.043^{*}$ & 7 & 2 & $3.92(0.77-20.00)$ & 0.101 \\
\hline & Log-additive & - & & & $1.22(0.89-1.66)$ & 0.218 & & & $1.43(0.82-2.46)$ & 0.204 \\
\hline LINC00824 & Allele & A & 362 & 331 & 1 & & 101 & 105 & 1 & \\
\hline rs7815944 & & G & 116 & 141 & $0.75(0.56-1.00)$ & 0.052 & 51 & 49 & $1.08(0.67-1.75)$ & 0.746 \\
\hline & Genotype & AA & 134 & 118 & 1 & & 34 & 39 & 1 & \\
\hline & & $A G$ & 94 & 95 & $0.87(0.59-1.26)$ & 0.454 & 33 & 27 & $1.41(0.71-2.81)$ & 0.332 \\
\hline & & GG & 11 & 23 & $0.43(0.20-0.91)$ & $0.028^{*}$ & 9 & 11 & $0.94(0.35-2.58)$ & 0.912 \\
\hline & Dominant & $\mathrm{AA}$ & 134 & 118 & 1 & & 34 & 39 & 1 & \\
\hline & & AG-GG & 105 & 118 & $0.78(0.54-1.12)$ & 0.179 & 42 & 38 & $1.28(0.67-2.43)$ & 0.457 \\
\hline & Recessive & $A A-A G$ & 228 & 213 & 1 & & 67 & 66 & 1 & \\
\hline & & GG & 11 & 23 & $0.45(0.22-0.96)$ & $0.037^{*}$ & 9 & 11 & $0.81(0.31-2.08)$ & 0.655 \\
\hline & Log-additive & - & & & $0.75(0.56-1.00)$ & 0.052 & & & $1.08(0.68-1.71)$ & 0.753 \\
\hline
\end{tabular}


Table 4 (continued)

$p$ values were calculated by logistic regression analysis adjusted by age and gender

Bold indicate that $p<0.05$ means the data is statistically significant

COPD chronic obstructive pulmonary disease, SNP single nucleotide polymorphism, OR odds ratio, $95 \% \mathrm{Cl}$ 95\% confidence interval

genotyping. Primer design (Additional file 1: Table S1) and data management are performed based on corresponding supporting software. About $10 \%$ of subjects were repeatedly genotyped for quality control, and the results were consistent.

\section{Statistical analysis}

Sample $t$ test or $x^{2}$ test were used to evaluated the distribution of age and gender between COPD patients and healthy controls. HWE of selected SNPs in controls was detected by a goodness-of-fit $\chi^{2}$ test. Logistic analysis adjusted by age and gender were applied to estimate the genetic contribution of selected SNPs to COPD susceptibility by calculating odds ratios (OR) and $95 \%$ confidence intervals (CI). Multifactor dimensionality reduction (MDR) analysis was used for analyze genegene interaction. Analysis of Variance (ANOVA) was used to evaluate the association between genotypes of LINC01414/LINC00824 variants and clinical characteristics of COPD patients. Data analyses were conducted using SPSS 20.0, PLINK 1.0.7, and MDR software. A $p$ value $<0.05$ was defined as statistical significance.

\section{Results}

\section{Participant characteristics.}

The participants consisted of 315 cases (239 males and 76 females, $71.9 \pm 10.1$ years) and 314 controls (237 males and 77 females, $71.2 \pm 6.8$ years). Table 1 summarized the features of participants, including age, gender, smoking, body mass index (BMI), complication, clinical symptoms (wheezing, dyspnea, chest distress), respiratory rate, pulse rate, forced vital capacity (FVC), forced the first second of expiratory volume (FEV1) and FEV1/FVC. No statistically significant difference in age $(p=0.307)$ and gender $(p=0.926)$ distribution was found.

\section{Correlation of selected polymorphisms with COPD risk}

Three SNPs (rs6994670 and rs298207 in LINC01414, rs7815944 in LINC00824) of the controls were consistent with HWE. The MAF of all the SNPs in this group were $>5 \%$ (Table 2). The prevalence of LINC01414 rs6994670 G-allele frequencies was lower in COPD patients than in controls $(\mathrm{OR}=0.73,95 \% \mathrm{CI} 0.56-0.94$, $p=0.015)$.

The genetic polymorphisms of selected SNPs were related to COPD susceptibility, as shown in Table 3. Rs699467 in LINC01414 might be a protective factor for
COPD occurrence under the dominant $(\mathrm{OR}=0.71,95 \%$ CI $0.51-0.97, p=0.034)$ and additive $(\mathrm{OR}=0.73,95 \% \mathrm{CI}$ $0.56-0.95, p=0.018)$ models. For LINC01414 rs298207, AA genotype was seen more frequent in COPD-patients compared with GG $(\mathrm{OR}=2.87,95 \%$ CI 1.30-6.36, $p=0.009)$ or $\mathrm{GG}-\mathrm{GA}(\mathrm{OR}=2.88,95 \%$ CI $1.31-6.31$, $p=0.008)$ genotype. Carriers of GG genotype of rs7815944 in LINC00824 had a lower frequent in COPDpatients compared with AA genotype (OR $=0.55,95 \% \mathrm{CI}$ $0.30-0.99, p=0.047)$ and AA-AG genotype $(\mathrm{OR}=0.56$, $95 \%$ CI 0.31-0.99, $p=0.046$ ).

\section{Stratification analysis for the genetic correlation by age, gender and smoking}

We also evaluated the contribution of confounding factors (age, gender and smoking status) to the genetic relationship between selected polymorphisms and COPD risk, as listed in Tables 4 and 5. When stratified analysis by age (Table 4), rs7815944 was associated with a reduced COPD risk under the allele $(\mathrm{OR}=0.71, p=0.034)$, genotype $(\mathrm{OR}=0.29, p=0.005)$, recessive $(\mathrm{OR}=0.30$, $p=0.005)$ and additive $(\mathrm{OR}=0.68, p=0.023)$ models in the subjects aged $>70$ years. Rs6994670 was observed to reduce the risk of COPD in the allele $(\mathrm{OR}=0.61$, $p=0.012), \quad$ genotype $(\mathrm{OR}=0.57, \quad p=0.037 ; \quad$ and $\mathrm{OR}=0.33, p=0.031)$, dominant $(\mathrm{OR}=0.52, p=0.012)$ and additive $(\mathrm{OR}=0.57, p=0.007)$ models among the subjects with age $\leq 70$ years. Rs298207 seem associated to development of COPD (OR=7.94, $p=0.009$; and $\mathrm{OR}=8.47, p=0.006)$ at age $\leq 70$ years.

In the stratified analysis by gender (Table 4), rs298207 and rs7815944 variants contributed to COPD risk in males. In which, rs298207-AA genotype was seen more frequent in COPD-patients compared with GG $(\mathrm{OR}=2.53, p=0.046)$ or GG-GA $(\mathrm{OR}=2.54, p=0.043)$ genotype among males. Rs7815944 was a protective factor for COPD susceptibility $(\mathrm{OR}=0.43, p=0.028$; and $\mathrm{OR}=0.45, p=0.037)$ in males.

Stratified analysis by smoking status (Table 5), we found that rs7815944 was associated with a reduced susceptibility of COPD in the allele $(\mathrm{OR}=0.45$, $p=0.040)$, genotype $(\mathrm{OR}=0.17, p=0.044)$, recessive $(\mathrm{OR}=0.16, p=0.031)$ models among former smokers. However, no significant association of these SNPs with COPD risk in current smokers and never smokers was found. 


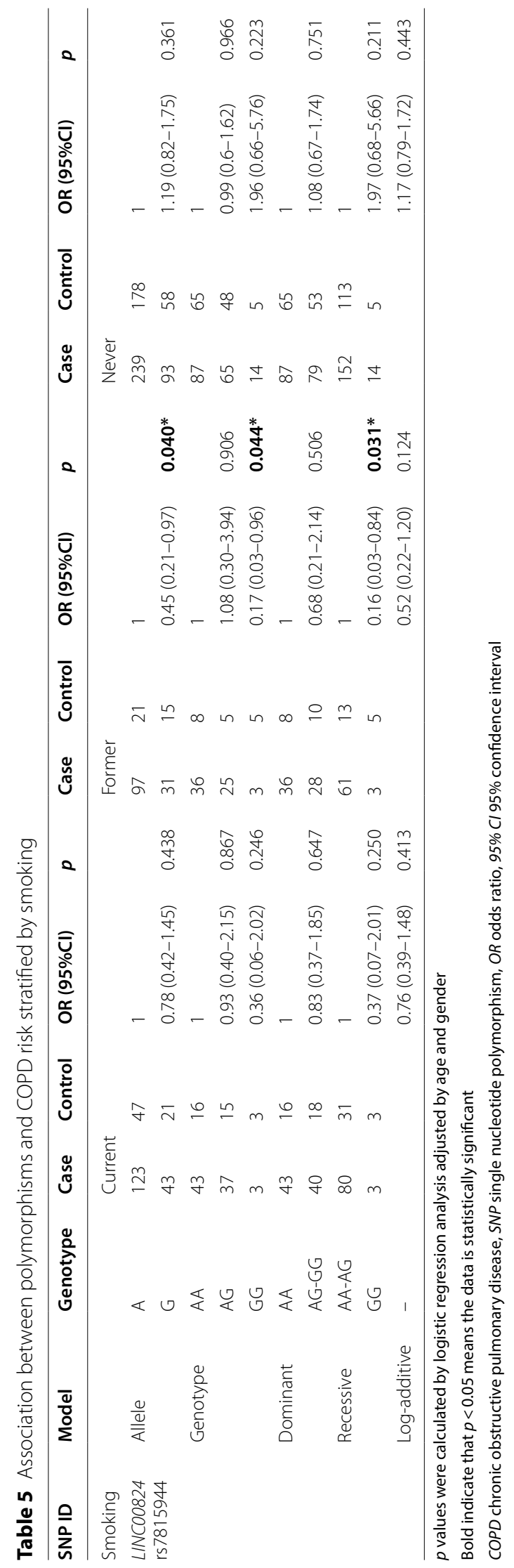


Table 6 Association of polymorphisms with dyspnea and wheezing in COPD patients

\begin{tabular}{|c|c|c|c|c|c|c|c|c|c|c|}
\hline \multirow[t]{2}{*}{ SNP ID } & \multirow[t]{2}{*}{ Model } & \multirow[t]{2}{*}{ Genotype } & \multicolumn{4}{|c|}{ COPD with dyspnea } & \multicolumn{4}{|c|}{ COPD with wheezing } \\
\hline & & & Yes & No & OR $(95 \% \mathrm{Cl})$ & $p$ & Yes & No & OR (95\%Cl) & $p$ \\
\hline \multirow{10}{*}{$\begin{array}{l}\text { LINC01414 } \\
\text { rs298207 }\end{array}$} & \multirow[t]{2}{*}{ Allele } & G & 180 & 242 & 1 & & 239 & 179 & 1 & \\
\hline & & A & 48 & 82 & $0.79(0.52-1.18)$ & 0.246 & 65 & 59 & $0.83(0.55-1.23)$ & 0.349 \\
\hline & \multirow[t]{3}{*}{ Genotype } & GG & 76 & 90 & 1 & & 94 & 71 & 1 & \\
\hline & & GA & 28 & 62 & $0.50(0.29-0.88)$ & $0.016^{*}$ & 51 & 37 & $1.03(0.60-1.74)$ & 0.925 \\
\hline & & $\mathrm{AA}$ & 10 & 10 & $0.91(0.34-2.45)$ & 0.852 & 7 & 11 & $0.40(0.14-1.13)$ & 0.083 \\
\hline & \multirow[t]{2}{*}{ Dominant } & GG & 76 & 90 & 1 & & 94 & 71 & 1 & \\
\hline & & GA-AA & 38 & 72 & $0.56(0.33-0.94)$ & $0.029^{*}$ & 58 & 48 & $0.88(0.54-1.45)$ & 0.615 \\
\hline & \multirow[t]{2}{*}{ Recessive } & GG-GA & 104 & 152 & 1 & & 145 & 108 & 1 & \\
\hline & & AA & 10 & 10 & $1.16(0.44-3.05)$ & 0.768 & 7 & 11 & $0.40(0.14-1.10)$ & 0.075 \\
\hline & Log-additive & - & & & $0.72(0.47-1.08)$ & 0.110 & & & $0.80(0.54-1.18)$ & 0.260 \\
\hline \multirow{10}{*}{$\begin{array}{l}\text { LINC00824 } \\
\text { rs7815944 }\end{array}$} & \multirow[t]{2}{*}{ Allele } & A & 170 & 242 & 1 & & 237 & 169 & 1 & \\
\hline & & G & 60 & 90 & $0.95(0.65-1.39)$ & 0.788 & 69 & 77 & $0.64(0.44-0.93)$ & $0.021^{*}$ \\
\hline & \multirow[t]{3}{*}{ Genotype } & $\mathrm{AA}$ & 62 & 87 & 1 & & 89 & 58 & 1 & \\
\hline & & $A G$ & 46 & 68 & $0.95(0.57-1.59)$ & 0.843 & 59 & 53 & $0.72(0.44-1.20)$ & 0.209 \\
\hline & & GG & 7 & 11 & $0.61(0.21-1.75)$ & 0.358 & 5 & 12 & $0.22(0.07-0.67)$ & $0.008^{*}$ \\
\hline & \multirow[t]{2}{*}{ Dominant } & AA & 62 & 87 & 1 & & 89 & 58 & 1 & \\
\hline & & AG-GG & 53 & 79 & $0.89(0.55-1.47)$ & 0.660 & 64 & 65 & $0.63(0.39-1.02)$ & 0.059 \\
\hline & \multirow[t]{2}{*}{ Recessive } & AA-AG & 108 & 155 & 1 & & 148 & 111 & 1 & \\
\hline & & GG & 7 & 11 & $0.63(0.22-1.74)$ & 0.369 & 5 & 12 & $0.25(0.08-0.76)$ & $0.014^{*}$ \\
\hline & Log-additive & - & & & $0.86(0.58-1.29)$ & 0.472 & & & $0.59(0.40-0.89)$ & $0.011^{*}$ \\
\hline
\end{tabular}

$p$ values were calculated by logistic regression analysis adjusted by age and gender

Bold indicate that $p<0.05$ means the data is statistically significant

COPD chronic obstructive pulmonary disease, SNP single nucleotide polymorphism, OR odds ratio, $95 \% \mathrm{Cl}$ 95\% confidence interval

\section{Correlation of selected polymorphisms with clinical symptoms in COPD patients}

The correlation of selected polymorphisms with clinical symptoms in COPD patients was also assessed, and the results was shown in Table 6. We found the association between rs298207 genotype and COPD patients with dyspnea $(\mathrm{OR}=0.50, p=0.016$; and $\mathrm{OR}=0.56$, $p=0.029)$. Moreover, our result displayed that rs7815944 was related to COPD patients with wheezing under the allele $(\mathrm{OR}=0.64, p=0.021)$, genotype $(\mathrm{OR}=0.22, p=0.008)$, recessive $(\mathrm{OR}=0.25, p=0.014)$ and additive $(\mathrm{OR}=0.59, p=0.011)$ models.

\section{MDR analysis for gene-gene interaction}

MDR analysis was analyzed to evaluate the contribution of gene-gene interaction to COPD risk. Figure 1 revealed the additive effect between LINC01414 rs6994670-GG, LINC01414 rs298207-AA, LINC00824 rs7815944-GG towards COPD susceptibility. The interactions of these SNPs was displayed as the dendrogram and Fruchterman-Reingold (Fig. 2). Our results demonstrated that LINC01414 rs6994670 was the best onefactor model for COPD risk (testing accuracy $=0.5468$, $\mathrm{CVC}=10 / 10, p=0.0188$, Table 7). Furthermore, the twofactor model (LINC01414 rs6994670 and LINC00824 rs7815944) was found to be the best multi-loci model for COPD risk (testing accuracy $=0.5518, C V C=10 / 10$, $p=0.0037)$.

\section{The association between selected variants and clinical characteristics of COPD patients}

The association between LINC01414/ LINC00824 SNPs and clinical indicators in COPD patients was assessed, as displayed in Table 8. We found that the genotypes of LINC00824 rs7815944 was associated with respiratory rate of COPD patients $(p=0.022)$. However, no statistically association was observed on rs6994670 and rs298207 in LINC01414. 


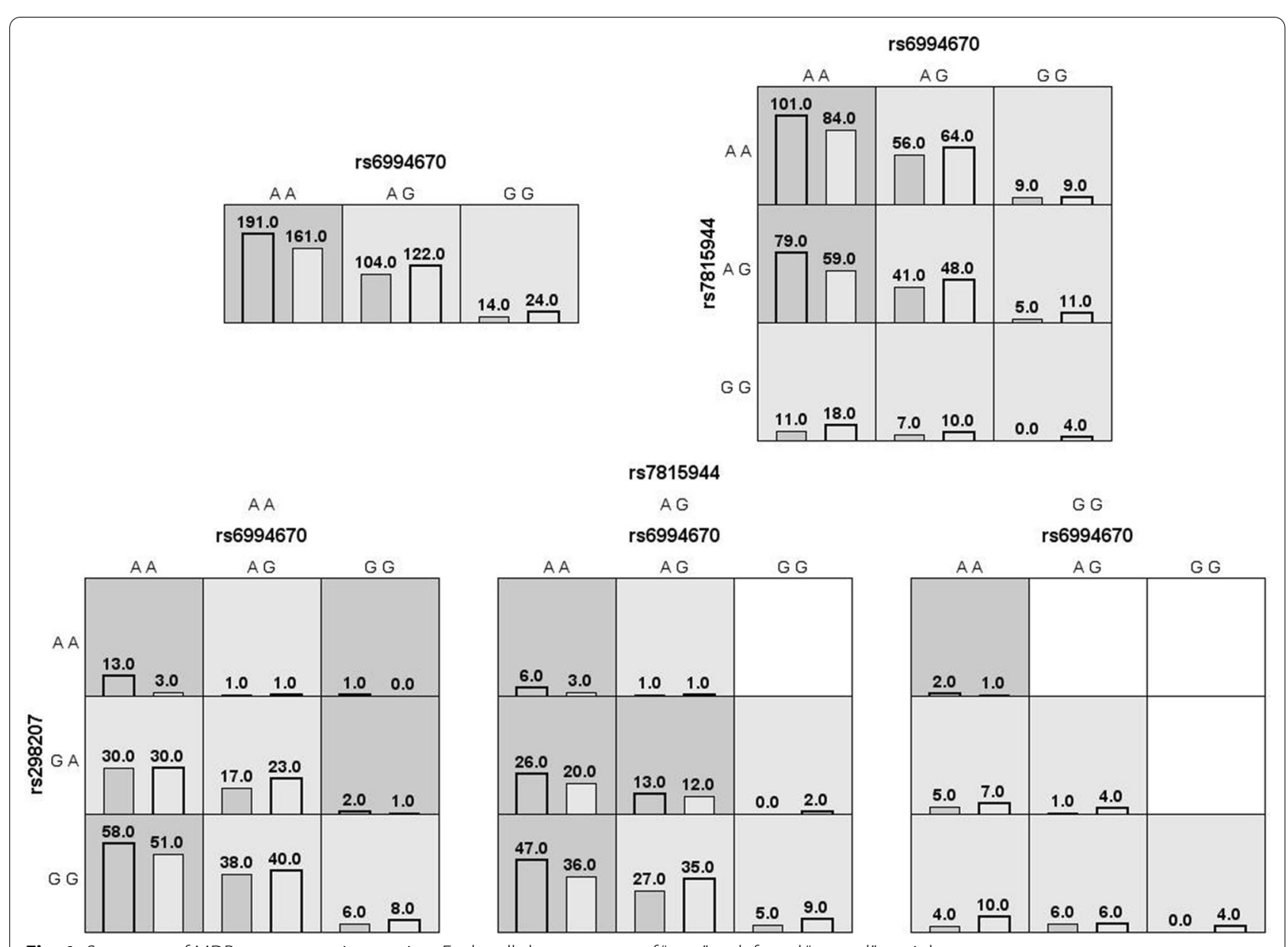

Fig. 1 Summary of MDR gene-gene interaction. Each cell shows counts of "case" on left and "control" on right

\section{Discussion}

In our study, rs699467 in LINC01414 and rs7815944 in LINC00824 might be protective factors for COPD occurrence, while LINC01414 rs298207 was associated with the increased risk of COPD in the whole population. Specially, age, gender, and smoking status might contributed to the association of these polymorphisms with COPD risk. Moreover, we found the association between rs298207 genotype and COPD patients with dyspnea, and rs7815944 was related to COPD patients with wheezing. Our findings firstly indicated that
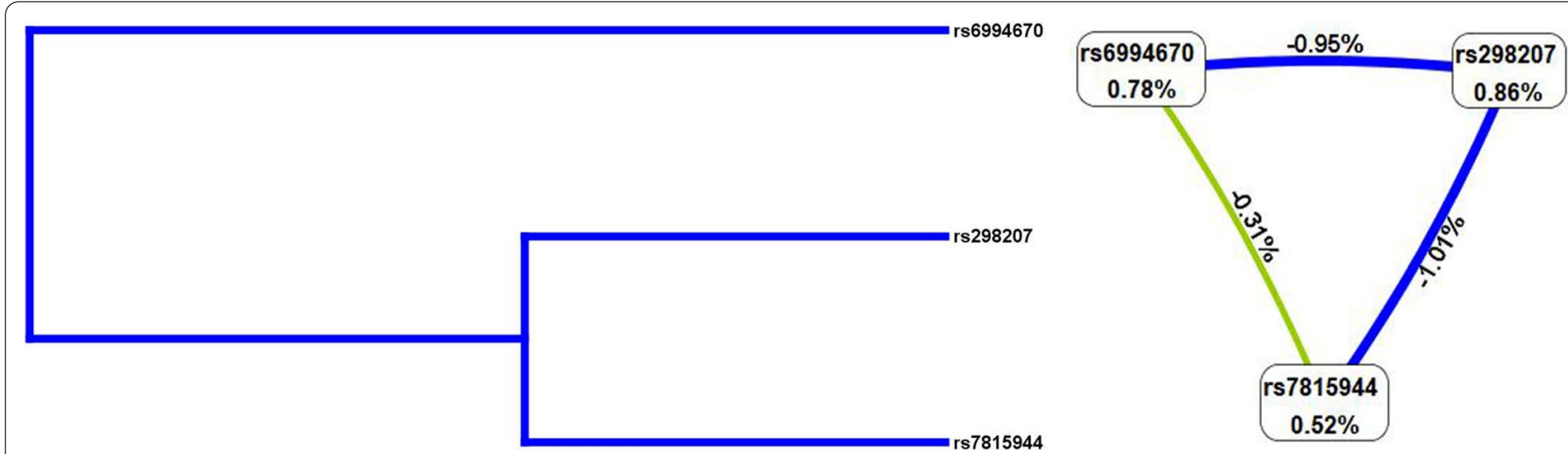

Fig. 2 Gene-gene interaction dendrogram and Fruchterman-Reingold 
Table 7 MDR analysis of gene-gene interaction for COPD risk

\begin{tabular}{|c|c|c|c|c|}
\hline Model & Training Bal. Acc & Testing Bal. Acc & CVC & $p$ \\
\hline LINC01414 rs6994670 & 0.5468 & 0.5468 & $10 / 10$ & 0.0188 \\
\hline LINC01414 rs6994670, LINC00824 rs7815944 & 0.5591 & 0.5518 & $10 / 10$ & 0.0037 \\
\hline $\begin{array}{l}\text { LINC01414 rs6994670, LINC01414 rs298207, LINC00824 } \\
\text { rs7815944 }\end{array}$ & 0.5688 & 0.508 & $10 / 10$ & 0.0012 \\
\hline
\end{tabular}

$p$ values were calculated using $x^{2}$ tests

Bold indicate that $p<0.05$ indicates statistical significance

MDR multifactor dimensionality reduction, Bal. Acc. balanced accuracy, CVC cross-validation consistency, OR odds ratio, CI confidence interval

Table 8 Association of clinical characteristics with genotypes of candidate SNPs among COPD patients

\begin{tabular}{|c|c|c|c|c|}
\hline \multirow[t]{2}{*}{ Variables } & \multicolumn{4}{|c|}{ LINC01414 rs6994670 } \\
\hline & $A A$ & AG & GG & $p$ \\
\hline Respiratory rate, times/min & $22.24 \pm 2.35$ & $22.49 \pm 2.73$ & $21.70 \pm 1.57$ & 0.519 \\
\hline Pulse rate, times/min & $86.50 \pm 11.07$ & $86.86 \pm 12.81$ & $78.20 \pm 7.63$ & 0.078 \\
\hline FVC, L & $2.01 \pm 0.71$ & $1.90 \pm 0.66$ & $2.03 \pm 0.42$ & 0.665 \\
\hline FEV1, L & $1.23 \pm 0.57$ & $1.20 \pm 0.68$ & $1.20 \pm 0.41$ & 0.932 \\
\hline FEV1/FVC, \% & $52.18 \pm 11.83$ & $48.55 \pm 11.23$ & $57.65 \pm 13.46$ & 0.133 \\
\hline \multirow[t]{2}{*}{ Variables } & \multicolumn{4}{|c|}{ LINC01414 rs298207 } \\
\hline & $\overline{A A}$ & GA & GG & $p$ \\
\hline Respiratory rate, times/min & $22.15 \pm 2.94$ & $22.29 \pm 2.43$ & $22.37 \pm 2.46$ & 0.914 \\
\hline Pulse rate, times/min & $85.05 \pm 13.57$ & $87.86 \pm 12.44$ & $85.81 \pm 11.12$ & 0.357 \\
\hline FVC, L & $2.00 \pm 0.64$ & $1.89 \pm 0.56$ & $2.02 \pm 0.75$ & 0.555 \\
\hline FEV1, L & $1.28 \pm 0.54$ & $1.13 \pm 0.48$ & $1.27 \pm 0.67$ & 0.384 \\
\hline FEV1/FVC, \% & $5086 \pm 15.95$ & $53.44 \pm 210.66$ & $50.27 \pm 11.99$ & 0.387 \\
\hline \multirow[t]{2}{*}{ Variables } & \multicolumn{4}{|c|}{ LINC00824 rs7815944 } \\
\hline & $\overline{\mathrm{AA}}$ & AG & GG & $p$ \\
\hline Respiratory rate, times/min & $22.36 \pm 2.5$ & $22.48 \pm 2.49$ & $20.78 \pm 1.26$ & 0.022 \\
\hline Pulse rate, times/min & $86.22 \pm 11.12$ & $86.32 \pm 12.28$ & $87.28 \pm 12.86$ & 0.937 \\
\hline FVC, L & $1.98 \pm 0.61$ & $2.00 \pm 0.76$ & $1.84 \pm 0.77$ & 0.777 \\
\hline FEV1, L & $1.19 \pm 0.52$ & $1.22 \pm 0.65$ & $1.41 \pm 0.81$ & 0.489 \\
\hline FEV1/FVC, \% & $52.35 \pm 11.23$ & $50.34 \pm 12.04$ & $50.46 \pm 16.01$ & 0.657 \\
\hline
\end{tabular}

$p$ values were calculated by Analysis of Variance (ANOVA)

Bold indicate that $p<0.05$ indicates statistical significance

COPD chronic obstructive pulmonary disease, BMI body mass index, FVC including forced vital capacity, FEV1 forced the first second of expiratory volume

LINC01414/LINC00824 polymorphisms might play a role in the occurrence of COPD.

LINC01414, located at chromosome 8q12.3, is a long intergenic non-protein coding RNA 1414. The function of LINC01414 has not been reported. LINC00824, located at chromosome $8 \mathrm{q} 24.21$, is also known as LINC01263. Genome-wide association studies reported that LINC00824 polymorphisms were associated with primary spontaneous pneumothorax and rheumatoid arthritis $[18,19]$. Here, we firstly found that rs699467 in
LINC01414 and rs7815944 in LINC00824 might be protective factors for COPD occurrence, while LINC01414 rs298207 increased the risk of COPD in the whole population.

The occurrence of COPD is caused by combined effects of genetic background, gender, smoking and an aging population [20]. COPD is the leading causes of disability and death in older people, and significant sex difference can be observed, especially deaths in older men [21]. We also evaluated the contribution of confounding factors 
(age and gender) to the genetic relationship between selected polymorphisms and COPD risk. Stratified analysis by age, rs7815944 was related to a reduced COPD risk in the subjects aged $>70$ years. Rs6994670 was associated with the reduced risk of COPD, while rs298207 might have a higher susceptibility to COPD at age $\leq 70$ years. In the stratified analysis by gender, rs298207 and rs7815944 variants were correlated with COPD risk in males. Our results suggested that the genetic contribution of LINC01414/LINC00824 variants to COPD risk was gender- and age-specific. It is generally believed that smoking is the main risk factor for COPD development [22]. Previously, LINC00824 was higher expression in current smokers compared with former smokers [16]. Stratified analysis by smoking status, we found that rs7815944 was associated with the reduced susceptibility of COPD in former smokers but not current smokers. These hinted that LINC00824 might have an important role in the COPD pathogenesis. The potential function of rs7815944 is unknown. We speculate that the biological function of rs7815944 may be involved in affecting the expression of I LINC00824, which needed to be further studied.

Several limitations in our study is unavoidable. First, the participants were Chinese Han population from a single center (the same hospital), therefore, the selection bias was inevitable and our results are not representative of other ethnic groups. Second, we only analyzed three SNPs in the LINCO1414/LINC00824 gene, and other polymorphisms and other lncRNA genes were not considered. Third, the functional effects of LINC01414/ LINC00824 variants in the pathogenesis of COPD were not explored.

\section{Conclusion}

In summary, we found that LINC01414 rs699467 and LINC00824 rs7815944 were associated with lower prevalence of COPD, while LINC01414 rs298207 was associated with the increased risk of COPD in the Chinese Han population. Our finding provided further insights into LINC01414/LINC00824 polymorphisms at risk of COPD occurrence and accumulated evidence for the genetic susceptibility of COPD.

\section{Supplementary Information}

The online version contains supplementary material available at https://doi. org/10.1186/s12890-021-01579-3.

Additional file 1. Primers sequence.

\section{Acknowledgements}

The authors thank all participants and volunteers in this study.
Authors' contributions

$X Z$ and $Y Z$ : drafted the work or revised it critically for important content; $Y Z$ and QL: performed the experiments; ML and YY: analyzed the data; YX: prepared the figures and/or tables; YD: conceived and designed the experiments. All authors have read and approved the manuscript.

Funding

This work was supported by Hainan Province Health Industry Research Project (20A200268).

\section{Availability of data and materials}

The datasets used or analyzed during the current study are available from the corresponding author on reasonable request.

\section{Declarations}

\section{Ethics approval and consent to participate}

The study was approved by the medical ethics committee of Hainan General Hospital and was in the Declaration of Helsinki. All the subjects signed a written informed consent.

\section{Consent for publication}

Written informed consent was obtained from the patient for publication of this report.

\section{Competing interests}

The authors declare that they have no conflict of interests.

Received: 4 March 2021 Accepted: 24 June 2021

Published online: 07 July 2021

References

1. Global Strategy for the Diagnosis, Management and Prevention of COPD, Global Initiative for Chronic Obstructive Lung Disease (GOLD); 2019. http://goldcopd.org/. Accessed 19 April 2019.

2. Chen $W$, Zheng R, Baade PD, Zhang S, Zeng H, Bray F, Jemal A, Yu XQ, He J. Cancer statistics in China, 2015. CA Cancer J Clin. 2016;66(2):115-32.

3. Quan F, Zhang F, Bai Y, Zhou L, Yang H, Li B, Jin T, Li H, Shao Y. Association of genetic polymorphisms with laryngeal carcinoma prognosis in a Chinese population. Oncotarget. 2017;8(6):10255-63.

4. Zhou M, Wang H, Zhu J, Chen W, Wang L, Liu S, Li Y, Wang L, Liu Y, Yin $\mathrm{P}$, et al. Cause-specific mortality for 240 causes in China during 1990-2013: a systematic subnational analysis for the Global Burden of Disease Study 2013. Lancet. 2016:387(10015):251-72.

5. Guan WJ, Zheng XY, Chung KF, Zhong NS. Impact of air pollution on the burden of chronic respiratory diseases in China: time for urgent action. Lancet. 2016;388(10054):1939-51.

6. Brandsma CA, Van den Berge M, Hackett TL, Brusselle G, Timens W. Recent advances in chronic obstructive pulmonary disease pathogenesis: from disease mechanisms to precision medicine. J Pathol. 2020;250(5):624-35.

7. Shrine N, Guyatt AL. New genetic signals for lung function highlight pathways and chronic obstructive pulmonary disease associations across multiple ancestries. Nat Genet. 2019;51(3):481-93.

8. Ragland MF, Benway CJ. Genetic advances in chronic obstructive pulmonary disease. Insights from COPDGene. Am J Respir Crit Care Med. 2019;200(6):677-90.

9. Nedeljkovic I, Lahousse L, Carnero-Montoro E, Faiz A, Vonk JM, de Jong $K$, van der Plaat DA, van Diemen CC, van den Berge M, Obeidat M, et al. COPD GWAS variant at 19q13.2 in relation with DNA methylation and gene expression. Hum Mol Genet. 2018;27(2):396-405.

10. Marchese FP, Raimondi I, Huarte M. The multidimensional mechanisms of long noncoding RNA function. Genome Biol. 2017;18(1):206.

11. Zhang J, Zhu Y, Wang R. Long noncoding RNAs in respiratory diseases. Histol Histopathol. 2018:33(8):747-56.

12. Qian Y, Mao ZD, Shi YJ, Liu ZG, Cao Q, Zhang Q. Comprehensive analysis of miRNA-mRNA-IncRNA networks in non-smoking and smoking patients with chronic obstructive pulmonary disease. Cell Physiol Biochem. 2018;50(3):1140-53 
13. Li N, Liu Y, Cai J. LnCRNA MIR155HG regulates M1/M2 macrophage polarization in chronic obstructive pulmonary disease. Biomed Pharmacother. 2019;117:109015.

14. Zhou S, Liu Y, Li M, Wu P, Sun G, Fei G, Xu X, Zhou X, Zhou L, Wang R. Combined effects of PVT1 and MiR-146a single nucleotide polymorphism on the lung function of smokers with chronic obstructive pulmonary disease. Int J Biol Sci. 2018;14(10):1153-62.

15. Chen X, Lu X, Chen J, Wu D, Qiu F, Xiong H, Pan Z, Yang L, Yang B, Xie C, et al. Association of nsv823469 copy number loss with decreased risk of chronic obstructive pulmonary disease and pulmonary function in Chinese. Sci Rep. 2017;7:40060.

16. Parker MM, Chase RP, Lamb A, Reyes A, Saferali A, Yun JH, Himes BE, Silverman EK, Hersh CP, Castaldi PJ. RNA sequencing identifies novel noncoding RNA and exon-specific effects associated with cigarette smoking. BMC Med Genom. 2017;10(1):58.

17. Pauwels RA, Buist AS, Calverley PM, Jenkins CR, Hurd SS. Global strategy for the diagnosis, management, and prevention of chronic obstructive pulmonary disease. NHLBI/WHO Global Initiative for Chronic Obstructive Lung Disease (GOLD) Workshop summary. Am J Respir Crit Care Med. 2001;163(5):1256-76.

18. Sousa I, Abrantes P, Francisco V, Teixeira G, Monteiro M, Neves J, Norte A, Robalo Cordeiro C, Moura ESJ, Reis E, et al. Multicentric Genome-wide association study for primary spontaneous pneumothorax. PLoS ONE. 2016;11(5):e0156103.

19. Aslam MM, John P, Fan KH, Bhatti A, Aziz W, Ahmed B, Feingold E, Demirci FY, Kamboh MI. Investigating the GWAS-implicated loci for rheumatoid arthritis in the Pakistani population. Dis Markers. 2020;2020:1910215.

20. Koch M, Butt T. Characteristics and health burden of the undiagnosed population at risk of chronic obstructive pulmonary disease in China. BMC Public Health. 2019;19(1):1727.

21. Mattiuzzi C, Lippi G. Worldwide disease epidemiology in the older persons. Eur Geriatr Med. 2020;11(1):147-53.

22. Osei AD, Mirbolouk M, Orimoloye OA, Dzaye O, Uddin SMI, Benjamin EJ, Hall ME, DeFilippis AP, Bhatnagar A, Biswal SS, et al. Association between E-cigarette use and chronic obstructive pulmonary disease by smoking status: behavioral risk factor surveillance system 2016 and 2017. Am J Prev Med. 2020;58(3):336-42.

\section{Publisher's Note}

Springer Nature remains neutral with regard to jurisdictional claims in published maps and institutional affiliations.
Ready to submit your research? Choose BMC and benefit from:

- fast, convenient online submission

- thorough peer review by experienced researchers in your field

- rapid publication on acceptance

- support for research data, including large and complex data types

- gold Open Access which fosters wider collaboration and increased citations

- maximum visibility for your research: over 100M website views per year

At BMC, research is always in progress.

Learn more biomedcentral.com/submissions 